\section{The Effect of Cigarette Smoking And Low-Level Laser Irradiation in RANK/RANKL/OPG Expression}

\author{
Larissa Nogueira Soares Ribeiro ${ }^{10}$, Patricia Maria Monteiro ${ }^{1}\left[{ }^{10}\right.$, Gabriel Dessotti \\ Barretto $^{10}$, Kelly Galisteu Luiz ${ }^{\circledR}$, Sandra Yasuyo Fukada Alves ${ }^{3}$, Maria \\ Bernadete Sasso Stuani ${ }^{1} \mathbb{D}$
}

\begin{abstract}
The objective of this study was to investigate the effects of low-level laser therapy (LLLT) and cigarette smoke on alveolar socket osteoclastogenesis signaling after tooth extraction, in rats. Sixty male Wistar rats were randomly assigned to four groups with 15 animals each: Control Group (with right maxillary molar extraction - ME), Experimental I (with ME and LLLT), Experimental II (with ME and cigarette smoke) and Experimental III group (with ME, LLLT and cigarette smoke). Euthanasia was performed at 3,7 and 14 days postoperative. qRT-PCR was used to evaluate expression of Tnfrsf11a (RANK), Tnfsf11 (Rankl) and Tnfrsf11b (OPG). Data were submitted to statistical analysis using two-way ANOVA followed by Bonferroni test $(\alpha=0.05)$. There was an upregulation of RANK, RANKL and OPG genes over all the time of healing in Exp I group compared to control group. Exp II group showed a decreased expression of all genes over time, whereas Exp III genes expression were higher than Exp II values but lower than Control and Exp I values over time. The results of this study concluded that the LLLT had a positive effect, whereas cigarette smoke had a negative effect on RANK, RANKL and $\mathrm{OPG}$ gene expression in bone remodeling process.
\end{abstract}

\author{
'Department of Pediatric Clinics, \\ School of Dentistry of Ribeirão \\ Preto, USP - Universidade de São \\ Paulo, Ribeirão Preto, SP, Brazil \\ ${ }^{2}$ Department of Orthodontics, School \\ of Dentistry of Rio de Janeiro, UFRJ \\ - Universidade Federal do Rio de \\ Janeiro, Rio de Janeiro, RJ, Brazil \\ ${ }^{3}$ Departament of Physics and \\ Chemistry, School of Pharmaceutical \\ Sciences of Ribeirão Preto, USP \\ - Universidade de São Paulo, \\ Ribeirão Preto, SP, Brazil
}

Correspondence: Maria Bernadete Sasso Stuani, Avenida do Café s/n, 14040-404 Ribeirão Preto, SP, Brasil. Tel: +16-3315-4105. e-mail: bernadete@forp.usp.br

bone, tooth extraction, bone remodeling, RANK, RANKL, OPG.

\section{Introduction}

A favorable architecture of the alveolar ridge with sufficient alveolar bone volume is essential to obtain a functional and esthetic prosthetic rehabilitation, however the alveolar crest height is often lowered after surgical tooth extraction performed as pretreatment before prosthetic treatment. Therefore, knowledge about the healing process at extraction sites is essential to avoid insufficient bone volume. Alveolar socket bone healing after tooth extraction is a complex process, which involves tissue repair and regeneration. It encompasses chemotaxis of different cells into the wound, differentiation of mesenchymal cells to osteoprogenitor cells, proliferation of the committed bone-forming cells, synthesis of extracellular matrix, mineralization of osteoid, maturation, and bone remodeling (1).

Remodeling and healing of the bone tissues depend on maintaining a delicate balance between bone resorption by osteoclasts and bone formation by osteoblasts (2). Acceleration of alveolar socket healing could be a good strategy to improve residual alveolar ridge preservation.

Since remodeling bone requires controlled inflammatory process, various studies have investigated the effect of lowlevel laser therapy (LLLT) on pain relief, inflammation control and modulation of bone resorption and apposition during orthodontic tooth movement (3). In fact, the utilization of LLLT for accelerating the bone healing can be considered. It is a safe and relatively non-invasive technique, with minimal discomfort and without the risk of drug interactions and side effects (4). In this context, the use of LLLT may be beneficial after oral surgeries and its beneficial effects on bone repair after tooth extraction has been described in some studies $(5,6)$.

Nicotine, due to its toxic effects, causes severe changes in bone metabolism, such as an imbalance in proliferation, differentiation and cell expression (7), inhibition of the synthesis of specific angiogenic growth factors (8), besides a reduction in the alkaline phosphatase concentration and the production of type I collagen by osteoblasts (9). Some of the effects of nicotine may impair the repair process, such as the release of catecholamines that decrease tissue perfusion and altered fibroblast metabolism (10), as well as decreased proliferation of red blood cells, macrophages and fibroblasts (11). Other components of the smoke are still related to changes in the repair process, such as carbon monoxide, which decreases tissue oxygenation and hydrogen cyanide that inhibits oxidative metabolism and transport of oxygen at the cellular level $(10,11)$.

Little is known regarding the role of LLLT on metabolic pathway during the bone remodeling after tooth extraction. Although there are some reports demonstrating the effect of LLLT on remodeling bone, most of them showing an acceleration on remodeling bone process compared to the control group $(12,13)$, there is a lack of studies on the effect of LLLT correlating bone metabolism at molecular and cellular level, as well as in the alveolar bone healing 
after cigarette smoke exposure.

Receptor activator of nuclear factor-kappa B (RANK), RANK ligand (RANKL) and osteoprotegerin (OPG) system plays an important role in inducing bone remodeling $(14,15)$. RANKL and its two receptors RANK and OPG, were shown to play a role in the remodeling process because they are important osteoclastogenesis regulatory molecules. RANKL is a downstream regulator of osteoclast formation and activation, through which many hormones and cytokines produce their osteoresorptive effect (14). In bone, RANKL is expressed by osteoblast cell lineage and periodontal ligament (PDL) cells (16) and it exerts its effects after binding to RANK receptor on the cell surface of osteoclast lineage cells as an osteoclast differentiating factor. This binding leads to rapid differentiation of hematopoietic osteoclast precursors to mature osteoclasts. OPG is a secreted tumor necrosis factor (TNF) receptor member produced by osteoblastic cells and competes with RANK for RANKL binding. The biologic effects of OPG on bone cells include inhibition of terminal stages of osteoclast differentiation, activation of matrix osteoclasts suppression and accelerating osteoclast apoptosis (15). RANKL and OPG act as positive and negative regulators of osteoclastogenesis, $(16)$ (16). Any imbalance in the communication between OPG, RANK, and RANKL proteins can lead to alterations in the quality of the formed mineralized tissue (15).

New bone formation is known to occur after tooth extraction. Although there are several studies in humans and animals (17), regarding the association of RANKL, RANK and OPG levels, there is no information about these biomarkers in alveolar bone in response to LLLT and cigarette smoke exposure. The present study evaluated osteoclastogenesis signaling in tooth socket in the presence of low-level laser therapy and exposure to cigarette smoke, after tooth extraction in rats, at different times of healing.

\section{Material and Methods}

This animal study was carried out in accordance with the ethical principles of animal experimentation and the Brazilian norms for the practical, educational, and scientific uses of vivisection and the experimental protocol was approved by the Animal Ethics Committee at the Universidade de São Paulo, Ribeirão Preto, Brazil (Authorization Protocol No - 1.173.58.0). Sixty male Wistar albinus rats (mean weight $180 \pm 10 \mathrm{~g}$ ) were assigned by blind randomization methods to four groups: Control Group ( $n=15$, with right maxillary molar extraction $M E)$, Experimental I ( $n=15$, with ME and laser applied to the socket - LLLT), Experimental II ( $n=15$, with ME and cigarrete smoking exposure - CS) and Experimental III group ( $n=15$, with ME, LLLT and CS). These groups were divided into subgroups (five rats per subgroup) according to the observation time point - 3, 7 and 14 days - after tooth extraction. The animals were housed five per cage in a room with a $12 / 12 \mathrm{~h} \mathrm{light/dark} \mathrm{cycles,} \mathrm{temperature} \mathrm{of} 24^{\circ} \pm 2^{\circ} \mathrm{C}$, humidity of $45-55 \%$ and they received a standard diet and water ad libitum during the entire experimental period.

\section{Tooth Extraction and Study Design}

Tooth extractions were performed under sterile conditions and anesthesia: the animals received an intramuscular injection of xylazine hydrochloride (Dopaser ${ }^{\circledR}$, Laboratório Calier do Brasil, Ltda, Osasco, Brazil; $0.025 \mathrm{~mL} / 100 \mathrm{~g}$ body weight) for muscular relaxation associated with ketamine hydrochloride (Ketamin ${ }^{\circledR}$; Cristália Produtos Químicos Farmacêuticos Ltda, Itapira, Brazil; $0.05 \mathrm{~mL} / 100 \mathrm{~g}$ body weight). Under general anesthesia, the maxillary right first molar of all animals $(n=60)$ were luxated and pulled out of the sockets in a non-traumatic manner, and bleeding was controlled by pressing the wound with a dry tampon. The molar was extracted in each rat with a dental explorer adapted to rat molars. An atraumatic surgical technique was used, which allowed tooth extraction without postoperative complications. The sockets were curetted and abundantly irrigated, aiming for removal of residual fragments of hard and soft tissues that could interfere with healing. The animals received a dose of paracetamol drops (Medley ${ }^{\circledR}$; Campinas, SP, Brazil) diluted in distilled water $(0.05 \mathrm{~mL} / 100 \mathrm{~g}$ body weight), intramuscularly, for post-operative analgesia.

\section{Laser Devices and Laser Irradiation Procedures}

To avoid bias from a potential systemic effect of LLLT, no internal controls were used. After extracting the teeth and controlling bleeding, the extraction sockets of all the rats of Exp I and III groups were irradiated with a $980 \mathrm{~nm}$ galliumaluminum-arsenide (GaAlAs) diode laser device (Photon Laser, DMC Equipaments, São Carlos, SP, Brazil; wave length 830 nm, $30 \mathrm{~mW}, \mathrm{CW}$ and spot of $0.00785 \mathrm{~cm}^{2}$ area). The irradiation was administered under anesthesia by placing the end of the optical fiber tip in light contact and aligned perpendicular with the sockets of the right side. Irradiation was performed immediately after extraction, corresponding to a total energy dosage of $54 \mathrm{~J} / \mathrm{cm}^{2}$, and a single application lasting $0.42 \mathrm{~s}$, and then carried out daily for 3 consecutive days. These conditions had been determined by previous experiments (18). The treatment regime for the control group (sham group) was the same as for the experimental group, except that the laser device was not switched on.

\section{Cigarette Smoke Exposure}

The cigarette smoke exposure of the animals was performed according to Nociti et al. (19). Briefly, it is used a 
transparent acrylic container with dimensions of $45 \times 25 \times 20$ $\mathrm{cm}^{3}$, composed of 2 chambers interconnected by a hole. In the first place were stored cigarettes on. In this part there was also an entrance through which air was pumped, forming a chain that carries the smoke to the second chamber, where the animals were. In the second chamber there was another orifice that gave discharge to the pumped air (Fig. 1). The animals exposed to cigarette smoke underwent a 3-week pre-adaptation period. After the right molar extraction, the animals were exposed to the smoke of 5 cigarettes for two daily periods of $3 \mathrm{~min}$ each, according to the recommended interval of days for each group.

Animal Euthanasia, RNA Extraction, Reverse Transcription (RT) and Quantitative Polymerase Chain Reaction (0-PCR) Analysis

For the qRT-PCR experiment, five rats in each group were used on days 3,7 and 14 . After the experimental time, the animals were euthanized by overdose of anesthetic and the area of the extraction socket bone in the molar region was exposed by peeling off the palatal mucosa with

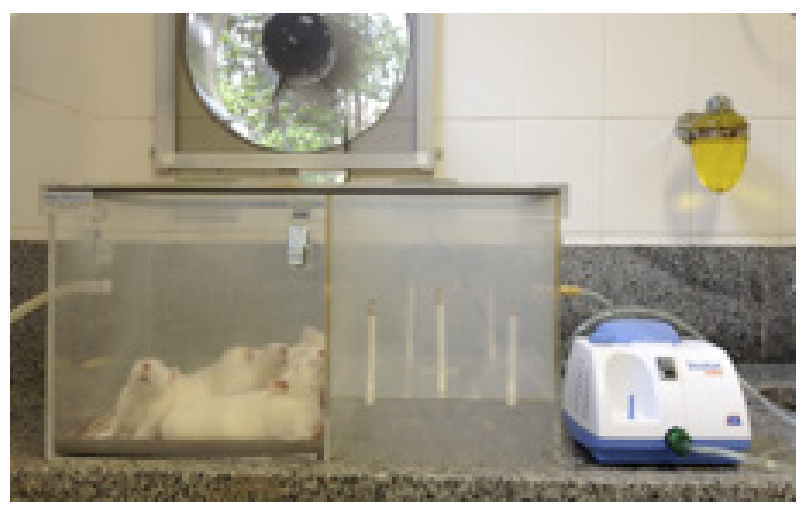

Figure 1. Chamber for cigarette smoke exposure.

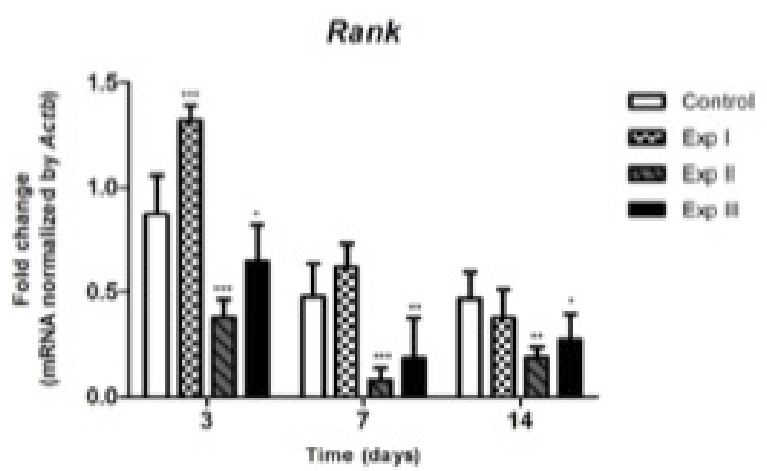

Figure 2. Fold change of mRNA of Tnfrsf11a (RANK) gene expression for Exp I, Exp II, Exp III and Control groups over time. ${ }^{*} p<0.05,{ }^{* *} p<0.01$, ${ }^{* * *} \mathrm{p}<0.001$, was considered statistically different. a scalpel. The newly formed tissue in the right maxillary alveolar socket was gently collected en bloc with a carbide bur (\#FG1112, KG Sorensen) and the specimens were stored in Eppendorfs at $-80^{\circ} \mathrm{C}$ to gene expressions analysis. The tissue was used to RNA extraction and complementary DNA (cDNA) synthesis. To produce the cDNA were used 2 $\mu \mathrm{g}$ of total RNA of each sample. The cDNA products were analyzed by q-PCR using TaqMan ${ }^{\circledR}$ Gene Expression Master Mix (Applied Biosystems, Foster City, CA, USA) and primers/ probe for Tnfrsf11b (OPG - Rn00563499_m1), Tnfrsf11a (RANK - Rn01426423_m1), Tnfsf11 (RANKL - Rn00589289_ m1) and Actb (Beta-actin - Rn00667869_m1; constitutive gene). q-PCR was run on StepOne Plus ${ }^{\circledR}$ machine (Applied Biosystems). Experiments were run in duplicate and water was used as negative control; control groups without tooth extraction at 3 days were used as positive control. Amplification conditions were: denaturation at $95^{\circ} \mathrm{C}(10$ min) and 40 cycles at $95^{\circ} \mathrm{C}(15 \mathrm{~s})$ and $60^{\circ} \mathrm{C}$ for $1 \mathrm{~min}$. For $m R N A$ analysis, the relative level of gene expression was calculated in reference to Actb expression using the cycle threshold (Ct) method.

\section{Statistical Analysis}

The results were analyzed using the cycle threshold (Ct) values based on the formula: Relative Expression Level $(\mathrm{QR})=2-\Delta \Delta \mathrm{Ct}$. Analysis of variance (two-way ANOVA) and Bonferroni test were used to compare all measurements. Statistical significance was found at $p<0.05$. Statistical analyses were performed using the GraphPad Prism version 5.0 software (GraphPad software ${ }^{\circledR}$, Inc.; La Jolla, CA, USA).

\section{Results}

There was an upregulation of Tnfrsf11a gene, which encodes RANK receptor, in Exp I group compared to C group at $3(p<0.001)$ and 7 days of healing. The peak of gene

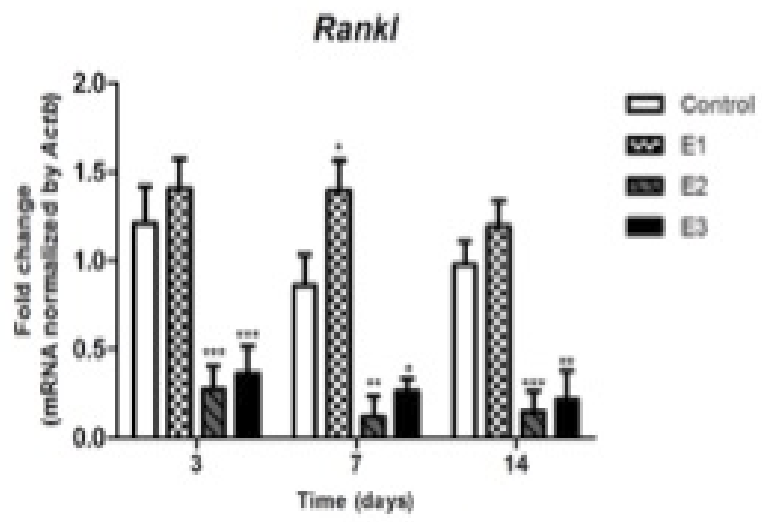

Figure 3. Fold change of mRNA Tnfsf11 (RANKL) gene expression for Exp I, Exp II, Exp III and Control groups over time. ${ }^{*} p<0.05,{ }^{* *} p<0.01,{ }^{* * *} p<0.001$, was considered statistically different. 
expression was observed at 3 days in Exp I group compared to 7 and 14 days $(p<0.001)$. The Exp II group presented the lowest Tnfrsf11 a gene expression in all periods, in relation to the control group $(p<0.001)$. A similar result was observed in Exp III group (Fig. 2).

Tnfsf11 gene, which encodes soluble factor RANKL, was also upregulated in Exp I group compared to Control group, at all experimental times $(p<0.05)$. Tnfsf11 gene expressed a similar pattern of RANK gene in Exp I group over time $(p<0.05)$. There was a peak of Tnfsf11 expression in Exp I group at 3 and 7 days compared to 14 days. The Exp II and III showed a decreased expression of RANKL over time $(p<0.05)$ (Fig. 3).

There was a significant upregulation of Tnfrsf11b gene, which encodes OPG, in Exp I group, compared to $C$ at 3 $(p<0.05), 7$ and 14 days $(p<0.001)$. At $3(p<0.001)$ and 7 days $(p<0.05)$ Exp II showed a decreased gene expression compared to $C$ group. There was also a decreased expression of Tnfrsf11b gene in Exp III group at 3 days ( $p<0.001)$ (Fig. 4).

\section{Discussion}

After tooth extraction, bone formation plays an important role in alveolar socket wound healing.

Alveolar bone remodeling consists of an interaction of bone resorption by osteoclasts and bone formation by osteoblasts. This study used alveolar bone after tooth extraction in rats as a model to evaluate the effect of LLLT and cigarette smoke exposure on bone metabolism and bone turnover. LLLT consists of non-thermal irradiation at wavelengths between visible light and the nearinfrared range; the irradiated cells absorb the light, triggering intracellular signaling cascades that can lead to various biological effects (20), such as cell growth, proliferation and differentiation. It has been shown that LLLT accelerates

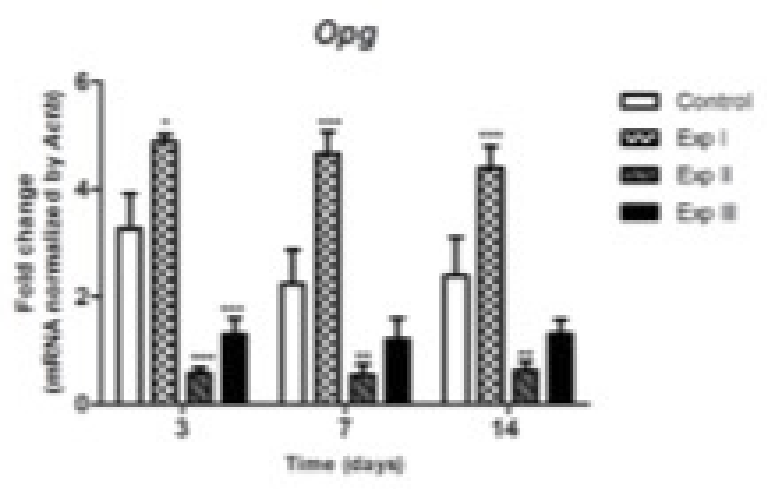

Figure 4. Fold change of mRNA of Tnfrsf11b (OPG) gene expression for Exp I, Exp II, Exp III and Control groups over time. ${ }^{*} p<0.05,{ }^{* *} p<0.01$, ${ }^{* * *} \mathrm{p}<0.001$, was considered statistically different. the process of wound healing $(12,13,18,20)$, increases blood flow and it promotes the release and secretion of vascular growth factor related to angiogenesis (12) allowing a more adequate supply of oxygen and nutrients to guarantee the needs of the proliferative phase in the healing process. On the other hand, nicotine and other toxic substances found in cigarette smoke $(19,21)$ promote inhibition of bone repair after guided bone regeneration and inhibit the expression of many cytokines including those associated with neovascularization (21), and osteoblastic differentiation (22).

RANKL, RANK and OPG play a key role in bone remodeling process. RANKL is expressed by osteoblasts and bone marrow stromal cells, whereas its receptor RANK is expressed in preosteoclasts and other cells from this lineage. The interaction between RANKL and RANK stimulates osteoclastic formation, fusion, activation, differentiation and survival by activation of several transcription factors that regulate osteoclastogenesis, thus resulting in bone resorption. OPG is produced by osteoblasts and other cells and acts as a decoy receptor that competes with RANKL for binding to its receptor RANK. This interaction inhibits osteoclastic proliferation and differentiation and consequently prevents bone resorption.

It was observed an upregulation on gene expression of RANK and RANKL on the initial periods of healing in Exp I group, whereas OPG gene expression was upregulated during the whole period of study for this group. It seems that LLLT leads to a gene expression more favorable to osteoclastogenesis during initial periods of healing, while formation bone stimulus is provided throughout the whole period of study. LLLT-treated osteoblast cells also showed an increase in RANKL gene expression comparing to alendronate-treated osteoblast cells (23).

Exp II and Exp III groups had an expressive and statistically significant reduction of RANK, RANKL and OPG gene expression during all periods analyzed in relation to the Control group. The Exp II group was the one that presented the lowest gene expression, showing a harmful effect of cigarette smoke on gene expression of the studied bone biomarkers. Gene expression evaluation of mediators related to bone resorption in the human periodontal ligament cells treated with nicotine demonstrated a reduction in OPG expression and an increase in RANKL expression, suggesting a stimulus for bone resorption in the activity pattern of these cells (24). Li-Zheng et al. (25) collected and cultured periodontal ligament cells after extraction of $1^{\circ}$ premolar, with addition of nicotine for $72 \mathrm{~h}$, and verified larger levels of RANKL gene expression after exposure of these cells to nicotine, whereas there was inhibition of OPG expression, resulting in a RANKL / OPG ratio directed to bone resorption. These findings from the literature agree in part with the 
present study. Considering that this study was performed in vivo, it is likely that the modulation of these genes activity is linked to a complex regulatory system, whereas in vitro evaluations characterize isolated cell responses that are not connected to other regulatory factors existing in a living organism. In addition, the cellular gene expression in these in vitro studies was evaluated in relation to the effect of nicotine, which is the major component of cigarette smoke, but not exclusive. In the present study, the animals were exposed to cigarette smoke and all the harmful substances that constitute it, which could justify the difference of response in the observed gene expression.

Exp III group showed a slight tendency to increase RANK gene expression levels during all periods of study, comparing to Exp II group, but they were not as high as $C$ and Exp I group. RANKL and OPG gene expression levels were lower than $C$ through all periods of study. Although LLLT showed a positive effect on the bone biomarkers gene expression studied, it was not enough to reverse the damaging effects of cigarette smoke.

The elucidation of the RANK/RANKL/OPG system has vastly increased our understanding of the mechanisms underlying the bone remodeling process. Therefore, our data showed that LLLT promoted a better alveolar socket healing in rats after tooth extraction, as evidenced by the increased bone biomarkers gene expression, whereas cigarette smoke inhalation interfered negatively in this process.

\section{Resumo}

0 objetivo deste estudo foi investigar os efeitos da terapia a laser de baixo nivel (LLLT) e a fumaça de cigarro na sinalização da osteoclastogênese do alvéolo após extração dentária, em ratos. Sessenta ratos Wistar machos foram distribuidos aleatoriamente em quatro grupos com 15 animais cada: Grupo de controle (com extração do molar superior direito (EM), Experimental I (EM e LLLT), Experimental II (EM e fumaça de cigarro) e Grupo Experimental III (EM, LLLT e fumaça de cigarro). A eutanásia foi realizada aos 3, 7 e 14 dias após a extração. 0 qRT-PCR foi utilizado para avaliar a expressão de Tnfrsf11a (RANK), Tnfsf11 (RANKL) e Tnfrsf11b (OPG). Os dados foram submetidos à análise estatística usando two-way ANOVA seguido do teste de Bonferroni $(\alpha=0,05)$. Houve um aumento na expressão dos genes RANK, RANKL e OPG ao longo do tempo de cicatrização no grupo Exp I em comparação com o grupo controle. 0 grupo Exp II mostrou uma expressão diminuida de todos os genes ao longo do tempo, enquanto a expressão dos genes do grupo Exp III foi superior aos valores observados em Exp II, mas inferiores aos valores do grupo Controle e Exp I ao longo do tempo. Os resultados deste estudo concluiram que o LLLT tem um efeito positivo, enquanto a fumaça de cigarro possui efeito prejudicial na expressão gênica de RANK, RANKL e OPG no processo de remodelação óssea.

\section{Acknowledgements}

This research was supported by a grant from The Brazilian agency FAPESP. Larissa Nogueira Soares Ribeiro thanks to CAPES for scholarship.

\section{References}

1. Lalani Z, Wong M, Brey EM, Mikos AG, Duke PJ. Spatial and temporal localization of transforming growth factor- $\beta 1$, bone morphogenetic protein-2, and platelet-derived growth factor- $\alpha$ in healing tooth extraction sockets in a rabbit model. J Oral Maxillofac Surg 2003;61:1061-1072.

2. Rodan GA, Martin TJ. Therapeutic approaches to bone diseases. Science 2000;289:1508-1514.

3. Dalaie K, Hamedi R, Kharazifard MJ, Mahdian M, Bayat M. Effect of low-level laser therapy on orthodontic tooth movement: a clinical investigation. J Dent 2015;12:249-256.

4. Shaughnessy $T$, Kantarci $A$, Kau CH, Skrenes D, Skrenes $S$, Ma D. Intraoral photobiomodulation induced orthodontic tooth alignment: a preliminar study. BMC Oral Health 2016;16:30.

5. Korany NS, Mehanni SS, Hakam HM, El-Maghraby EM. Evaluation of socket healing in irradiated rats after diode laser exposure (histological and morphometric studies). Arch Oral Biol 2012;57:884-891.

6. Park JB, Ahn SJ, Kang YG, Kim EC, Heo JS, Kang KL. Effects of increased low-level diode laser irradiation time on extraction socket healing in rats. Lasers Med Sci 2015;30:719-726.

7. Rothem DE, Rothem L, Dahan A, Eliakim R, Soudry M. Nicotinic modulation of gene expression in osteoblast cells, MG-63. Bone 2011;48:903-909.

8. Theiss SM, Boden SD, Hair G, Titus L, Morone MA, Ugbo J. The effect of nicotine on gene expression during spine fusion. Spine 2000;25:25882594.

9. Tanaka H, Tanabe N, Suzuki N, Shoji M, Torigoe H, Sugaya A. Nicotine affects mineralized nodule formation by the human osteosarcoma cell line Saos-2. Life Sci 2005;77:2273-2284.

10. Nagaie $M$, Nishiura $A$, Honda $Y$, Fujiwara $S$, Matsumoto N. A comprehensive mixture of tobacco smoke components retards orthodontic tooth movement via the inhibition of osteoclastogenesis in a rat model. Int J Mol Sci 2014;15:18610-18622.

11. Tanaka H, Tanabe N, Kawato T, Nakai K, Kariya T, Matsumoto S, et al. Nicotine affects bone resorption and suppresses the expression of cathepsin K, MMP-9 and vacuolar-type $\mathrm{H}(+)$-ATPase $\mathrm{d} 2$ and actin organization in osteoclasts. PLoS One 2013;8:e59402.

12. Prado RP, Pinfildi CE, Liebano RE, Rochman BS, Ferreira LM. Effect of application site of low-level laser therapy in random cutaneous flap viability in rats. Photomed Laser Surg 2009;27:411-416.

13. Pinfildi CE, Liebano RE, Hochman BS, Enokihara MM, Lippert $R_{\text {, Gobbato }}$ $\mathrm{RC}$, et al. Effect of low-level laser therapy on mast cells in viability of the transverse rectus abdominis musculocutaneous flap. Photomed Laser Surg 2009;27:337-343.

14. Yamaguchi M. RANK/RANKL/OPG during orthodontic tooth movement. Orthod Craniofac Res 2009;12:113-119.

15. Manrique N, Pereira CC, Luvizuto ER, Sanchez Mdel P, Okamoto $T$, Okamoto $R$, et al. Hypertension modifies OPG, RANK, and RANKL expression during the dental socket bone healing process in spontaneously hypertensive rats. Clin Oral Investig 2015;19:13191327.

16. Ogasawara T, Yoshimine Y, Kiyoshima T, Kobayashi I, Matsuo K, Akamine A et al. In situ expression of RANKL, RANK, osteoprotegerin and cytokines in osteoclasts of rat periodontal tissue. J Periodontal Res 2004;39:42-49.

17. Kawasaki K, Shimizu N. Effects of low-energy laser irradiation on bone remodeling during experimental tooth movement in rats. Lasers Surg Med 2000; 26:282-291.

18. Silva AP, Petri AD, Crippa GE, Stuani AS, Stuani AS, Rosa AL et al. Effect of low level laser therapy after rapid maxillary expansion on proliferation and differentiation of osteoblastic cells. Lasers Med Sci 2012;27:777-783.

19. Nociti Junior FH, Cesar Neto JB, Carvalho MD, Sallum EA, Sallum AW. Intermittent cigarette smoke inhalation may affect bone volume around titanium implants in rats. J Periodontol 2002;73:982-987.

20. Briteño-Vázquez $M$, Santillán-Díaz $G$, González-Pérez $M$, GallegoIzquierdo T, Pecos-Martín D, Plaza-Manzano G, et al. Low power laser stimulation of the bone consolidation in tibial fractures of rats: a radiologic and histopathological analysis. Lasers Med Sci 2015;30:333338.

21. César-Neto JB, Benatti BB, Sallum EA, Casati, Nociti FH Jr. The 
influence of cigarette smoke inhalation and its cessation on the toothsupporting alveolar bone: a histometric study in rats. J Periodontal Res 2006;41:118-123.

22. Zheng LW, Ma L, Cheung LK. Changes in blood perfusion and bone healing induced by nicotine during distraction osteogenesis. Bone 2008:43:355-361.

23. Shin SH, Kim KH, Choi NR, Kim IR, Park BS, Kim YD, et al. Effect of lowlevel laser therapy on bisphosphonate-treated osteoblasts. Maxillofac Plast Reconstr Surg 2016;38:48.

24. Lee HJ, Pi SH, Kim Y, Kim HS, Kim SJ, Kim YS, et al. Effects of nicotine on antioxidant defense enzymes and RANKL expression in human periodontal ligament cells. J Periodontol 2009;80:1281-1288.

25. Li-Zheng W, Duo-Mo D, Ying-Feng L, Xin G, Zhi-Fei Z, Xiao-Jing W. Nicotine favors osteoclastogenesis in human periodontal ligament cells co-cultured with CD4+T cells by upregulating IL-1 $1 \beta$. Int J Molec Med 2013;31:938-942.

Received March 7, 2019

Accepted September 25, 2019 